\title{
A LEGITIMIDADE PARA FIRMAR ACORDOS DE LENIÊNCIA
}

\author{
THE LEGITIMACY TO SIGN PLEA BARGAIN AGREEMENT
}

\author{
Cintia Barudi Lopes ${ }^{1}$ \\ Flávia Piva Almeida Leite ${ }^{2}$ \\ Camila Pereira Mendonça ${ }^{3}$
}

\section{Resumo}

Este artigo analisa a legitimidade para firmar Acordo de Leniência, de acordo com o quanto previsto na Lei Anticorrupção $\mathrm{n}^{\circ} 12.846 / 2013$, especificamente com relação aos órgãos que exercem o controle da Administração Pública Federal. Com a edição da Lei Anticorrupção surgiu a possibilidade de celebração de Acordos de Leniência junto às pessoas jurídicas envolvidas em atos ilícitos cometidos em detrimento da Administração Pública, nacional ou estrangeira, em matérias diversas ao Direito Concorrencial já estabelecido na Lei Antitruste Brasileira. A metodologia empregada se consubstancia na técnica analítica, na qual serão avaliados os entes de

\footnotetext{
${ }^{1}$ Doutora pela Pontifícia Universidade Católica de São Paulo - PUC/SP, em direito administrativo (2017). Possui mestrado em Direitos Difusos e Coletivos pela Universidade Metropolitana de Santos (2009). Especialização com capacitação docente em direito constitucional pela Escola Superior de Direito Constitucional (2003). Graduada em direito pelas Faculdades Metropolitanas Unidas (1996). Atualmente é professora da Universidade Presbiteriana Mackenzie e do Centro Universitário das Faculdades Metropolitanas Unidas na disciplina de direito administrativo. Avaliadora do CONPEDI - Conselho Nacional de Pesquisa e Pós-Graduação em Direito. Diretora da Comissão de Direito Administrativo da $116^{\circ}$ Subseção do Jabaquara - São Paulo. Advogada. E-mail: c.barudi@uol.com.br

${ }^{2}$ Doutora em Direito Urbanístico pela Pontifícia Universidade Católica - PUC - São Paulo/SP, Mestre em Direito Constitucional pela Instituição Toledo de Ensino - ITE - Bauru/SP, Pós-graduada em Gerente de Cidades pela Fundação Armando Álvares Penteado - FAAP - São Paulo/SP. Docente da UNESP - Universidade Estadual Paulista "Julio de Mesquita Filho", Faculdade de Arquitetura, Artes e Comunicação - Campus Bauru. Docente permanente do Programa de Pós-Graduação em Direito da UNESP- Franca. E-mail: flavia.leite @unesp.br

${ }^{3}$ Bacharela em Direito pelo Centro Universitário das Faculdades Metropolitanas Unidas, advogada na Andrade Gutierrez Engenharia S/A com atuação em Direito Administrativo, especificamente em Ações Civis Públicas e processos nos Tribunais de Contas. E-mail: camilappereiram@outlook.com
} 
controle do Poder Executivo Federal e seus interesses na realização dos referidos instrumentos consensuais de leniência e, consequentemente, o entendimento que está sendo adotado pelo Poder Judiciário Brasileiro quanto à legitimidade para firmar os Acordos de Leniência e as medidas a serem adotadas para a resolução do conflito existente.

Palavras chave: Acordo de Leniência; Lei Anticorrupção; Administração Pública; Legitimidade; Atos ilícitos.

\begin{abstract}
This article analyzes the legitimacy to enter into a plea bargain agreement, following the amount provided for in anti-corruption law No. 12.846/2013, specifically concerning the new bodies to the exercise control of the Federal Public Administration. With an edition of the anti-corruption law, the possibility of execution of plea bargains agreements with legal entities using illicitly acts committed to the detriment of the public administration, national or foreign in several matters to the competition law. With an edition of the anti-corruption law, the possible execution of plea bargains agreements with legal entities using illicitly acts committed to the detriment of the public administration national or foreign in several matters to the competition law, already established in the Brazilian antitrust law. The methodology employed is embodied in the analytical technique in which the federal executive branch's control rights and its interests in the achievement of the leniency consensus indicator are allowed and, consequently the understanding of who is being adopted by the Brazilian judiciary as to the legitimacy agreements and the measure taken to solve existing conflicts.
\end{abstract}

Keywords: Plea Bargain Agreement; Anti-Corruption Law; Public administration; Legitimacy; Illicit acts.

\title{
INTRODUÇÃO
}

Nos últimos anos, o Brasil vem enfrentando diversas mudanças frente aos escândalos de corrupção que envolvem pessoas jurídicas e agentes públicos, conhecidos por toda a população, em razão de serem amplamente divulgados pela mídia. 
A investigação que deflagrou os atos de corrupção praticados foi iniciada pela Superintendência da Polícia Federal de Curitiba/PR e recebeu o nome de "Operação Lava-Jato". A referida operação deu início à uma série de descobertas de atos/crimes consubstanciados em improbidade administrativa, superfaturamento, lavagem de dinheiro, formação de cartel, fraude à licitação, corrupção passiva e ativa, bem como diversos outros que violam diretamente a Ordem Econômica.

Em vista desse cenário, as autoridades públicas se viram diante de uma série de irregularidades praticadas por pessoas físicas que se valeram de seus cargos públicos ou até mesmo de seu contato direto para com a Administração Pública, especialmente mediante a celebração de contratos através de licitação para a execução de projetos públicos, bem como com a realização de contratos de Concessão e de Parceria Público Privada.

Ocorre que, não obstante o envolvimento das pessoas físicas, ainda havia uma preocupação diretamente ligada ao regular funcionamento das pessoas jurídicas vítimas de seus administradores e controladores, as quais não poderiam ser totalmente prejudicadas em razão da ocorrência de atos lesivos e que se punidos, especialmente com uma possível declaração de inidoneidade, poderiam intensificar a crise econômica que abarcava o país.

Deste modo, visando o bom funcionamento da justiça bem como da Ordem Econômica, as autoridades públicas passaram a realizar o chamado Acordo de Leniência.

O Acordo de Leniência foi instituído no ordenamento jurídico brasileiro a partir da Lei $\mathrm{n}^{\circ}$ 12.846, de $1^{\circ}$ de agosto de 2013, popularmente conhecida como a Lei Anticorrupção e consiste em uma nova forma de combate aos atos lesivos praticados contra a Administração Pública e, consequentemente, aos seus cofres públicos, visando a rápida resolução das investigações, a responsabilização dos envolvidos e a continuidade das investigações, em razão dos atos e fatos narrados no âmbito do referido acordo.

Entretanto, atualmente há um conflito envolvendo os órgãos públicos que exercem o controle da Administração Pública Federal quanto aos legitimados para firmar os acordos junto às pessoas jurídicas lesadas. Tal fato gera extrema insegurança jurídica aos lenientes, visto que futuramente podem ser penalizados por outros órgãos por fatos já divulgados e que já estão sendo ressarcidos aos cofres públicos, por força de acordos firmados anteriormente. 
Sendo assim, necessária se faz a análise da legitimidade para a realização do Acordo de Leniência junto às pessoas jurídicas, bem como do conflito existente entre os órgãos que exercem o controle da Administração Pública Federal, com foco nas atuais discussões que norteiam o tema.

\section{O OBJETIVO PRÁtICO DA LENIÊNCIA E SUA INSERÇÃONO ORDENAMENTO JURÍDICO BRASILEIRO}

Primeiramente, antes de adentrar na análise da Lei Anticorrupção e do Acordo de Leniência previsto em seus dispositivos, é significativo tecer algumas considerações sobre a definição do objetivo prático da Leniência e sua inserção no ordenamento jurídico brasileiro.

O instrumento consensual da Leniência tem, independentemente da esfera em que lhe é utilizado, o objetivo de buscar resoluções eficazes ante aos atos praticados em detrimento da Administração Pública. Além deste caráter punitivo da Leniência, há também um viés repressivo para fazer cessar eventuais danos que ainda estejam sendo praticados ao interesse público.

Nesse sentido, em que pese a eficiência do poder administrativo sancionatório, a Leniência é de suma importância na resolução de esquemas de corrupção, pois é fato que sem a colaboração das pessoas jurídicas e das pessoas físicas envolvidas na prática dos atos ilícitos não seria possível a obtenção de resultados tão rápidos e efetivamente positivos ao Poder Público e à população brasileira, em especial, com o ressarcimento dos danos causados e com a devida punição dos agentes envolvidos.

Exemplificando melhor os meios adotados para a utilização da Leniência, necessária a exposição de trecho da decisão proferida pelo ex-juiz Federal Sérgio Fernando Moro, quando dahomologação de um dos acordos celebrados entre uma empreiteira e o Ministério Público Federal $^{4}$ :

Pode-se questionar a falta de punição proporcional ao crime em decorrência da leniência, mas trata-se de consequência do acordo e das vantagens obtidas por ele. Melhor ter informações e provas decorrentes do acordo, que possibilitem a persecução dos demais envolvidos, do que não ter qualquer elemento probatório e persecução nenhuma.

\footnotetext{
${ }^{4}$ Decisão proferida pelo ex-juiz Federal, atual Ministro da Justiça e Segurança Pública do Brasil, Sérgio Fernando Moro, no âmbito do processo n ${ }^{\circ}$ 5017783-68.2016.4.04.7000, em trâmite perante a $13^{\mathrm{a}}$ Vara Federal da Seção Judiciária do Paraná em Curitiba, na data de 05/05/2016.
} 
Além disso, com o acordo, preserva-se a própria existência da empresa e a continuidade de suas atividades, o que, apesar dos crimes, encontra justificativa em evitar os efeitos colaterais negativos na economia e nos empregos por ela gerados, direta ou indiretamente.

Deste modo, é necessário ressalvar que a figura consensual para a resolução de práticas delitivas já está inserida no ordenamento jurídico brasileiro há décadas em forma de colaboração. Neste instituto as pessoas físicas contribuem para o bom funcionamento da justiça em troca da obtenção de eventuais benefícios na esfera penal.

Entretanto, a possibilidade de realização de um instrumento de colaboração com a participação da pessoa jurídica diretamente ligada aos atos criminosos somente surgiu após inserção na Lei 8.884/1994 pela Lei $\mathrm{n}^{\circ}$ 10.149/2000 - Lei Antitruste Brasileira, que previu a possibilidade de realização de um Acordo de Leniência no âmbito da ocorrência de Crimes Concorrenciais contra a Ordem Econômica perante o Conselho Administrativo de Defesa Econômica - CADE.

Todavia, o Sistema de Defesa da Concorrência foi devidamente reestruturado e modernizado após a introdução da Lei $\mathrm{n}^{\circ}$ 12.529/2011 no ordenamento pátrio. A referida Lei também reestruturou a possibilidade de utilização do instituto da Leniência, criando o chamado "Programa de Leniência", sendo este o principal instrumento de combate a cartéis no Brasil.

Seguindo a linha de efetiva recomposição dos danos praticados contra ao patrimônio público e sua administração, em 2013 surgiu a chamada Lei Anticorrupção, dando finalmente a possibilidade de realização de Acordos de Leniência pelas empresas envolvidas no cometimento de atos ilícitos em matérias que vão além do Direito Concorrencial.

\section{LEI 12.846/2013 - A LEI ANTICORRUPÇÃO}

Importante esclarecer que o foco deste artigo é a análise da Legitimidade para firmar Acordo de Leniência. Não obstante, a referida análise não seria possível sem uma breve exposição acerca dos institutos que materializam a Lei Anticorrupção, que atualmente é um dos principais mecanismos, junto com a Constituição Federal da República, utilizados pelas autoridades públicas do país no combate à corrupção em âmbito nacional e estrangeiro. 
A Lei Anticorrupção foi aprovada, pelo Congresso Nacional, no ano de 2013. Entretanto, somente em 2015 foi editado e publicado perante o ordenamento jurídico brasileiro o Decreto Federal $n^{\circ} 8.420 / 2015$, que regulamentou sua aplicabilidade prática.

Essa Lei surgiu não apenas para punir os envolvidos nos atos lesivos ao erário público, como também para criar mecanismos de prevenção à corrupção, com a implantação de políticas de integridade em empresas privadas e em órgãos que compõem a administração pública. Para a efetividade desses mecanismos, a Lei também nos trouxe a importância da fiscalização através de auditorias realizadas especialmente para verificar a ocorrência de irregularidades.

Para elucidar melhor a questão, nas palavras de Valdir Moysés Simão e de Marcelo Pontes Vianna ${ }^{5}$, a Lei Anticorrupção:

Veio inaugurar, no ordenamento pátrio, a possibilidade de responsabilização administrativa e civil de pessoas jurídicas pela prática de atos lesivos contra a Administração Pública nacional e estrangeira. Com sua promulgação, o Estado passou a deter meios de sancionar pessoas jurídicas de forma efetiva. Anteriormente, a ação estatal ficava restrita à punição das pessoas naturais que agiam em nome das empresas ou, ainda, à aplicação de sanções judiciais ou administrativas de fundo contratual ou regulatório.

Deste modo, dentre os diversos aspectos positivos que abarcam a referida Lei, ainda visando o bom funcionamento da justiça, houve a inovação com a possibilidade de celebração do chamado "Acordo de Leniência" em matérias de atos lesivos ocorridos contra a Administração Pública em território nacional ou estrangeiro.

\section{O ACORDO DE LENIÊNCIA NO ÂMBITO DA LEI ANTICORRUPÇÃO}

O Acordo de Leniência foi instituído no ordenamento jurídico brasileiro pela Lei Anticorrupção $\mathrm{n}^{\mathrm{o}}$ 12.846/2013, em seu capítulo V, e possui como principal característica a possibilidade da negociação sob o comando de órgãos de controle com pessoas jurídicas envolvidas em atos ilícitos e interessadas em colaborar para o devido andamento das investigações.

\footnotetext{
5 SIMÃO, Valdir Moysés. O acordo de leniência na lei anticorrupção (livro eletrônico): histórico, desafios e perspectivas. Valdir Moysés Simão, Marcelo Pontes Vianna. São Paulo. Trevisan Editora, 2017.
} 
De acordo com o artigo 16, caput, da Lei Anticorrupção n 12.846/2013, os órgãos de controle poderão celebrar o referido Acordo de Leniência junto às pessoas jurídicas responsáveis pela prática de atos lesivos, desde que resultem: (i) na identificação dos demais envolvidos na infração, quando couber e; (ii) a obtenção célere de informações e documentos que comprovem o ilícito sob apuração.

Para que seja possível a realização deste acordo, é necessário o preenchimento, cumulativo, dos requisitos previstos no artigo 16 , parágrafo $1^{\circ}$ e seus incisos da Lei $12.846 / 2013$, que consistem nas seguintes condições:

I. a pessoa jurídica seja a primeira a se manifestar sobre seu interesse em cooperar para a apuração do ato ilícito;

II. a pessoa jurídica cesse completamente seu envolvimento na infração investigada a partir da data de propositura do acordo;

III. a pessoa jurídica admita sua participação no ilícito e coopere plena e permanentemente com as investigações e o processo administrativo, comparecendo, sob suas expensas, sempre que solicitada, a todos os atos processuais, até seu encerramento.

Com relação aos possíveis benefícios que podem ser auferidos às pessoas jurídicas lenientes (artigo 16, § $2^{\circ}$, Lei n ${ }^{\circ} 12.846 / 2013$ ), estas poderão obter a não publicação extraordinária da decisão condenatória pelos danos incorridos, a não declaração de inidoneidade, podendo assim, seguir com suas atividades normalmente podendo receber incentivos, subsídios, doações ou empréstimos de órgãos ou entidades públicas e de instituições financeiras públicas ou controladas pelo poder público. Além disso, a multa pelos danos causados ao erário poderá ser reduzida em até 2/3 (dois terços).

Nesse sentido, no artigo 16 da Lei 12.846/2013 há outras disposições que podem ser vistas como outros benefícios a serem obtidos com a realização do referido acordo, tais como:

$\S 5^{\circ}$ Os efeitos do acordo de leniência serão estendidos às pessoas jurídicas que integram o mesmo grupo econômico, de fato e de direito, desde que firmem o acordo em conjunto, respeitadas as condições nele estabelecidas.

$\S 6^{\circ}$ A proposta de acordo de leniência somente se tornará pública após a efetivação do respectivo acordo, salvo no interesse das investigações e do processo administrativo.

$\S 7^{\circ}$ Não importará em reconhecimento da prática do ato ilícito investigado a proposta de acordo de leniência rejeitada. 
Não obstante, a celebração do Acordo de Leniência interrompe o prazo prescricional dos atos ilícitos previstos na Lei Anticorrupção (artigo 16, § 9º , Lei 12.846/2013).

Entretanto, conforme disposição do $\S 3^{\circ}$, do artigo 16, da Lei 12.846/2013: “o Acordo de Leniência não exime a pessoa jurídica da obrigação de reparar integralmente o dano causado". Esta premissa é de suma importância, tendo em vista o fato de que o entendimento que é passado à população por meio das mídias sociais é de que os valores negociados no âmbito da celebração do acordo se dão com a efetiva redução do valor integral ao dano causado à Administração Pública, quando, na verdade, a redução se dá somente com relação ao valor da multa aplicada pelo órgão de controle a título de indenização pelos atos lesivos praticados.

Ainda mais importante do que a celebração do Acordo de Leniência, é o efetivo cumprimento de todos os termos compactuados entre as partes. Para que o acompanhamento do cumprimento do acordo seja eficaz, foi criado no âmbito do Poder Executivo Federal o Cadastro Nacional de Empresas Punidas - CNEP.

O CNEP, de acordo com o quanto previsto no artigo 22, da Lei 12.846/2013: "reunirá e dará publicidade às sanções aplicadas pelos órgãos ou entidades dos Poderes Executivo, Legislativo e Judiciário de todas as esferas de governo". Neste sistema deve conter, além das informações acerca das sanções aplicadas, a razão social, o CNPJ da pessoa jurídica, o tipo de sanção, a data de aplicação e a data final da vigência do efeito limitador ou impeditivo da sanção, quando for o caso.

O sistema foi criado com o propósito de dar publicidade para que todos os órgãos de controle da Administração Pública e a população brasileira acompanhem os desdobramentos do cumprimento dos Acordos de Leniência firmados. A atualização das informações deve ser realizada constantemente, incluindo eventual descumprimento, desde que este procedimento não venha a causar prejuízo às investigações e ao processo administrativo (artigo $22, \S 3^{\circ}$ e $4^{\circ}$ da Lei $12.846 / 2013)$.

Apesar dos grandes avanços no âmbito do combate à corrupção no Brasil, a Lei Anticorrupção mesmo deixando clara a legitimidade para firmar um Acordo de Leniência, conforme será visto a seguir, ainda há uma intensa discussão acerca da legitimidade que os órgãos que exercem o controle da Administração Pública Federal possuem. 


\section{A LEGITIMIDADE PARA FIRMAR O ACORDO DE LENIÊNCIADE ACORDO}

\subsection{CONTROLADORIA GERAL DA UNIÃO - CGU}

A Lei Anticorrupção deixou clara a legitimidade para firmar o Acordo de Leniência em âmbito federal, atribuindo-a à Controladoria Geral da União - $\mathrm{CGU}^{6}$, conforme se pode observar em seu quanto disposto no artigo 16 , parágrafo $10^{\circ}$ :

A Controladoria Geral da União - CGU é o órgão competente para celebrar os acordos de leniência no âmbito do Poder Executivo Federal, bem como no caso de atos lesivos praticados contra a administração pública estrangeira.

Ainda, no Decreto $\mathrm{n}^{\circ}$ 8.420/2015, que regulamenta a Lei 12.846/2013 e dispõe sobre a responsabilização administrativa objetiva de pessoas jurídicas pela prática de atos contra a administração pública, nacional ou estrangeira, há também a ressalva quanto à competência da Controladoria Geral da União - CGU para celebrar Acordo de Leniência, nos mesmos termos previstos na Lei Anticorrupção (artigo 29 do Decreto 8.420/2015).

Deste modo, não restam dúvidas de que a Controladoria Geral da União - CGU é a detentora da legitimidade, conforme atribuição lhe atribuída por vias legais, para celebrar os Acordos de Leniência no âmbito Federal.

\subsection{ADVOCACIA GERAL DA UNIÃO - AGU}

A Lei $n^{\circ}$ 12.846/2013 - Lei Anticorrupção, não previu em seus dispositivos a figura da Advocacia Geral da União - AGU.Entretanto, a Advocacia Geral da União - AGU é a instituição, devidamente prevista no artigo 131 da Constituição $\mathrm{Federal}^{7}$, responsável pela representação da União, judicial ou extrajudicialmente, a fim de defender os interesses do Poder Executivo Federal.

\footnotetext{
${ }^{6}$ A Controladoria-Geral da União (CGU) é o órgão de controle interno do Governo Federal responsável por realizar atividades relacionadas à defesa do patrimônio público e ao incremento da transparência da gestão, por meio de ações de auditoria pública, correição, prevenção e combate à corrupção e ouvidoria. A CGU também deve exercer, como Órgão Central, a supervisão técnica dos órgãos que compõem o Sistema de Controle Interno e o Sistema de Correição e das unidades de ouvidoria do Poder Executivo Federal, prestando a orientação normativa necessária (INSTITUCIONAL. Controladoria Geral da União. Disponível em: <https://www.cgu.gov.br/sobre/institucional> . Acesso em: 11 de out. de 2019).

${ }^{7}$ Art. 131. A Advocacia-Geral da União é a instituição que, diretamente ou através de órgão vinculado, representa a União, judicial e extrajudicialmente, cabendo-lhe, nos termos da lei complementar que dispuser sobre sua organização e funcionamento, as atividades de consultoria e assessoramento jurídico do Poder Executivo.
} 
Seguindo esta linha de raciocínio, mesmo que realizado o Acordo de Leniência entre a pessoa jurídica infratora e a Controladoria Geral da União - CGU, se verificados eventuais danos ao patrimônio público e a quaisquer interesses do Poder Executivo Federal, por outros meios sem que através dos termos sigilosos constantes no acordo celebrado, a Advocacia Geral da União AGU possuiria ampla legitimidade para requerer a reparação destes danos. Essa possibilidade consequentemente geraria uma insegurança jurídica às empresas lenientes, o que as fariam sentir que sua colaboração talvez não fosse tão benéfica a si mesmas, muito pelo o contrário, pensariam que de uma maneira indireta poderia ser utilizada em seu prejuízo.

Por esta razão, tornou-se imprescindível a composição de uma parceria entre a Controladoria Geral da União e a Advocacia Geral da União, visando fortalecer ainda mais os Acordos de Leniência firmados em âmbito federal, incentivando as pessoas jurídicas envolvidas em fatos ilícitos a colaborarem com o bom funcionamento da justiça e à recomposição dos danos causados em face da Administração Pública.

Em termos de formalização dessa parceria firmada entre os órgãos de controle, em 13 de dezembro de 2016, a Controladoria Geral da União e a Advocacia Geral da União assinaram uma portaria interministerial que, além de definir os procedimentos para celebração do Acordo de Leniência que trata a Lei $n^{\circ} 12.846 / 2013$, dispunha sobre a participação da Advocacia Geral da União nas negociações em âmbito federal.

Posteriormente, ante aos resultados positivos advindos desta parceria firmada, em 4 de agosto de 2019, foi assinada nova Portaria Conjunta reestruturando o procedimento de realização de Acordo de Leniência, destacando os termos e campos de atuação da Advocacia Geral da União, seja no momento das negociações, da celebração e, ainda mais importante, no acompanhamento do cumprimento dos acordos firmados.

Por outro lado, há também a figura do Ministério Público Federal, que nos últimos anos vem firmando Acordos de Leniência junto às empresas jurídicas envolvendo ilícitos praticados em detrimento da Administração Pública Federal, cuja legitimidade, conforme observado anteriormente, compete exclusivamente à Controladoria Geral da União. Este fato nos traz à discussão atual que norteia o meio jurídico brasileiro no que tange aos acordos administrativos celebrados em âmbito Federal. 


\section{O PAPEL DO MINISTÉRIO PÚBLICO FEDERAL NA ESFERA DO ACORDO DE LENIÊNCIA}

O Ministério Público é um órgão permanente, devidamente instituído e regulamentado pela Constituição Federal em seu Capítulo IV, Seção I, com previsão expressa em seus artigos 127 a 130. Esse órgão é essencial à função jurisdicional do Estado, e lhe é incumbida a defesa da ordem jurídica, do regime democrático e dos interesses sociais e individuais indisponíveis (artigo 127, Constituição Federal).

Instituído o órgão de proteção aos interesses, em especial, da coletividade e ao estrito cumprimento dos deveres legais, há uma divisão quanto aos Ministérios Públicos que abrangem o Poder Executivo Federal. De acordo com o exposto no artigo 128, I, alínea a,da Constituição Federal,o Ministério Público Federal consta na composição do Ministério Público da União.

Pois bem. O Ministério Público Federal é um dos principais órgãos que exercem o controle da Administração Pública Federal através do seu papel de custus legis, ou seja, como fiscal da Lei. Sua atuação como fiscal da Lei consiste no dever de garantir o estrito cumprimento de normas Constitucionais e Infraconstitucionais.

Além disso, judicialmente o Ministério Público Federal possui outras duas esferas de atuação, quais sejam: (i) civil e; (ii) penal. Na esfera civil ele atua em defesa dos interesses difusos, coletivos e individuais homogêneos (artigo 129, III da Constituição Federal) e, ainda, é titular legítimo para propor ação civil pública versando sobre matéria de Improbidade Administrativa em atos cometidos em detrimento ao patrimônio público Federal, de acordo com o quanto previsto na Lei de Improbidade Administrativa, em seus artigos $16^{8}$ e $17^{9}$.

Já com relação à atuação do Ministério Público Federal na esfera penal, a legitimidade para propor a ação penal pública é inteiramente sua. Esta legitimidade lhe foi atribuída pela Constituição Federal, em seu artigo 129, I e sucessivamente pelo Código Penal, artigo 100, em seu $\S 1^{\circ}$ e pelo Código de Processo Penal em seu artigo 24.

\footnotetext{
${ }^{8}$ Art. 16. Havendo fundados indícios de responsabilidade, a comissão representará ao Ministério Público ou à procuradoria do órgão para que requeira ao juízo competente a decretação do sequestro dos bens do agente ou terceiro que tenha enriquecido ilicitamente ou causado dano ao patrimônio público.

${ }^{9}$ Art. 17. A ação principal, que terá o rito ordinário, será proposta pelo Ministério Público ou pela pessoa jurídica interessada, dentro de trinta dias da efetivação da medida cautelar.
} 
Nessa lógica, e talvez este seja o aspecto mais relevante desta discussão, considerando a perspectiva da esfera penal (levando-se em conta a capacidade para punir penalmente os agentes envolvidos) e paralelamente a esfera civil (tendo em vista a legitimidade para requerer indenização por eventuais danos causados), a Lei no 8.429/02 que trata da Improbidade Administrativa e a Lei de Licitações $n^{\circ}$ 8.666/93, também atribuem ao Ministério Público a legitimidade para apurar e aplicar sanções referentes aos crimes incorridos nas referidas Leis(artigos $15^{10}, 16^{11}, 17^{12}$ e $22^{13}$ da Lei $\mathrm{n}^{\circ} 8.429 / 92$ e artigo $100^{14}$ da Lei $\left.\mathrm{n}^{\circ} 8.666 / 93\right)$, em ambas esferas.

Não obstante, no âmbito da Lei de Improbidade Administrativa, caso o Ministério Público não figurediretamente como parte, sua atuação como Fiscal da Lei se torna obrigatória, sob pena de nulidade dos atos advindos dos procedimentos em trâmite (artigo $17, \S 4^{\circ}$ da Lei $n^{\circ} 8.429 / 92^{15}$ ). Este fato reforça a necessidade da presença do Ministério Público Federal quando presentes eventuais atos lesivos de interesse da Administração Pública Federal previstos nesta Lei.

Cumpre esclarecer que na Lei de improbidade Administrativa não são punidos somente os agentes públicos, como também eventuais terceiros que induzem ou concorrem para a prática dos atos ímprobos ou que deles se beneficie (artigo $3^{\circ}$ da Lei 8.429/92).

Observados tais pontos, especialmente quanto à atuação do Ministério Público Federal no âmbito de suas atribuições provenientes da Lei de Improbidade Administrativa, da Lei de Licitações edo seu papel de detentor da legitimidade para propor ação penal pública, passar-se-á a análise dos atos lesivos à Administração Pública constantes na Lei Anticorrupção.

\footnotetext{
${ }^{10}$ Art. 15. A comissão processante dará conhecimento ao Ministério Público e ao Tribunal ou Conselho de Contas da existência de procedimento administrativo para apurar a prática de ato de improbidade.

${ }^{11}$ Art. 16. Havendo fundados indícios de responsabilidade, a comissão representará ao Ministério Público ou à procuradoria do órgão para que requeira ao juízo competente a decretação do sequestro dos bens do agente ou terceiro que tenha enriquecido ilicitamente ou causado dano ao patrimônio público.

${ }^{12}$ Art. 17. A ação principal, que terá o rito ordinário, será proposta pelo Ministério Público ou pela pessoa jurídica interessada, dentro de trinta dias da efetivação da medida cautelar.

${ }^{13}$ Art. 22. Para apurar qualquer ilícito previsto nesta Lei, o Ministério Público, de ofício, a requerimento de autoridade administrativa ou mediante representação formulada de acordo com o disposto no art. 14, poderá requisitar a instauração de inquérito policial ou procedimento administrativo.

${ }^{14}$ Art. 100. Os crimes definidos nesta Lei são de ação penal pública incondicionada, cabendo ao Ministério Público promovê-la.

${ }^{15}$ Art. $17, \S 4^{\circ}$. O Ministério Público, se não intervier no processo como parte, atuará obrigatoriamente, como fiscal da lei, sob pena de nulidade.
} 
Para tanto, imprescindível o confronto de alguns dispositivos desta Lei com a Lei de Improbidade Administrativa e com a Lei de Licitações:

\begin{tabular}{|c|c|}
\hline $\begin{array}{l}\text { Artigo } 5^{\circ} \text { da Lei } 12.646 / 2013 \text { - Lei Anticorrupção. Art. } 5^{\circ} \\
\text { Constituem atos lesivos à administração pública, nacional ou } \\
\text { estrangeira, para os fins desta Lei, todos aqueles praticados } \\
\text { pelas pessoas jurídicas mencionadas no parágrafo único do art. } \\
1^{\text {o }} \text {, que atentem contra o patrimônio público nacional ou } \\
\text { estrangeiro, contra princípios da administração pública ou } \\
\text { contra os compromissos internacionais assumidos pelo Brasil, } \\
\text { assim definidos: }\end{array}$ & $\begin{array}{l}\text { Artigo } 9^{\circ} \text { da Lei 8.429/92 - Lei de Improbidade } \\
\text { Administrativa. Constitui ato de improbidade } \\
\text { administrativa importando enriquecimento ilícito } \\
\text { auferir qualquer tipo de vantagem patrimonial } \\
\text { indevida em razão do exercício de cargo, mandato, } \\
\text { função, emprego ou atividade nas entidades } \\
\text { mencionadas no art. } 1^{\circ} \text { desta Lei, e notadamente: }\end{array}$ \\
\hline \multirow[b]{2}{*}{$\begin{array}{l}\text { I - prometer, oferecer ou dar, direta ou indiretamente, vantagem } \\
\text { indevida a agente público, ou a terceira pessoa a ele relacionada; }\end{array}$} & $\begin{array}{l}\text { I - receber, para si ou para outrem, dinheiro, bem } \\
\text { móvel ou imóvel, ou qualquer outra vantagem } \\
\text { econômica, direta ou indireta, a título de comissão, } \\
\text { percentagem, gratificação ou presente de quem } \\
\text { tenha interesse, direto ou indireto, que possa ser } \\
\text { atingido ou amparado por ação ou omissão } \\
\text { decorrente das atribuições do agente público; }\end{array}$ \\
\hline & $\begin{array}{l}\text { II - perceber vantagem econômica, direta ou } \\
\text { indireta, para facilitar a aquisição, permuta ou } \\
\text { locação de bem móvel ou imóvel, ou a contratação } \\
\text { de serviços pelas entidades referidas no art. } 1^{\circ} \text { por } \\
\text { preço superior ao valor de mercado; }\end{array}$ \\
\hline \multirow{2}{*}{$\begin{array}{l}\text { II - comprovadamente, financiar, custear, patrocinar ou de } \\
\text { qualquer modo subvencionar a prática dos atos ilícitos previstos } \\
\text { nesta Lei; } \\
\text { III - comprovadamente, utilizar-se de interposta pessoa física ou } \\
\text { jurídica para ocultar ou dissimular seus reais interesses ou a } \\
\text { identidade dos beneficiários dos atos praticados; }\end{array}$} & $\begin{array}{l}\text { III - perceber vantagem econômica, direta ou } \\
\text { indireta, para facilitar a alienação, permuta ou } \\
\text { locação de bem público ou o fornecimento de } \\
\text { serviço por ente estatal por preço inferior ao valor } \\
\text { de mercado; }\end{array}$ \\
\hline & $\begin{array}{l}\mathrm{V} \text { - receber vantagem econômica de qualquer } \\
\text { natureza, direta ou indireta, para tolerar a } \\
\text { exploração ou a prática de jogos de azar, de } \\
\text { lenocínio, de narcotráfico, de contrabando, de usura }\end{array}$ \\
\hline
\end{tabular}




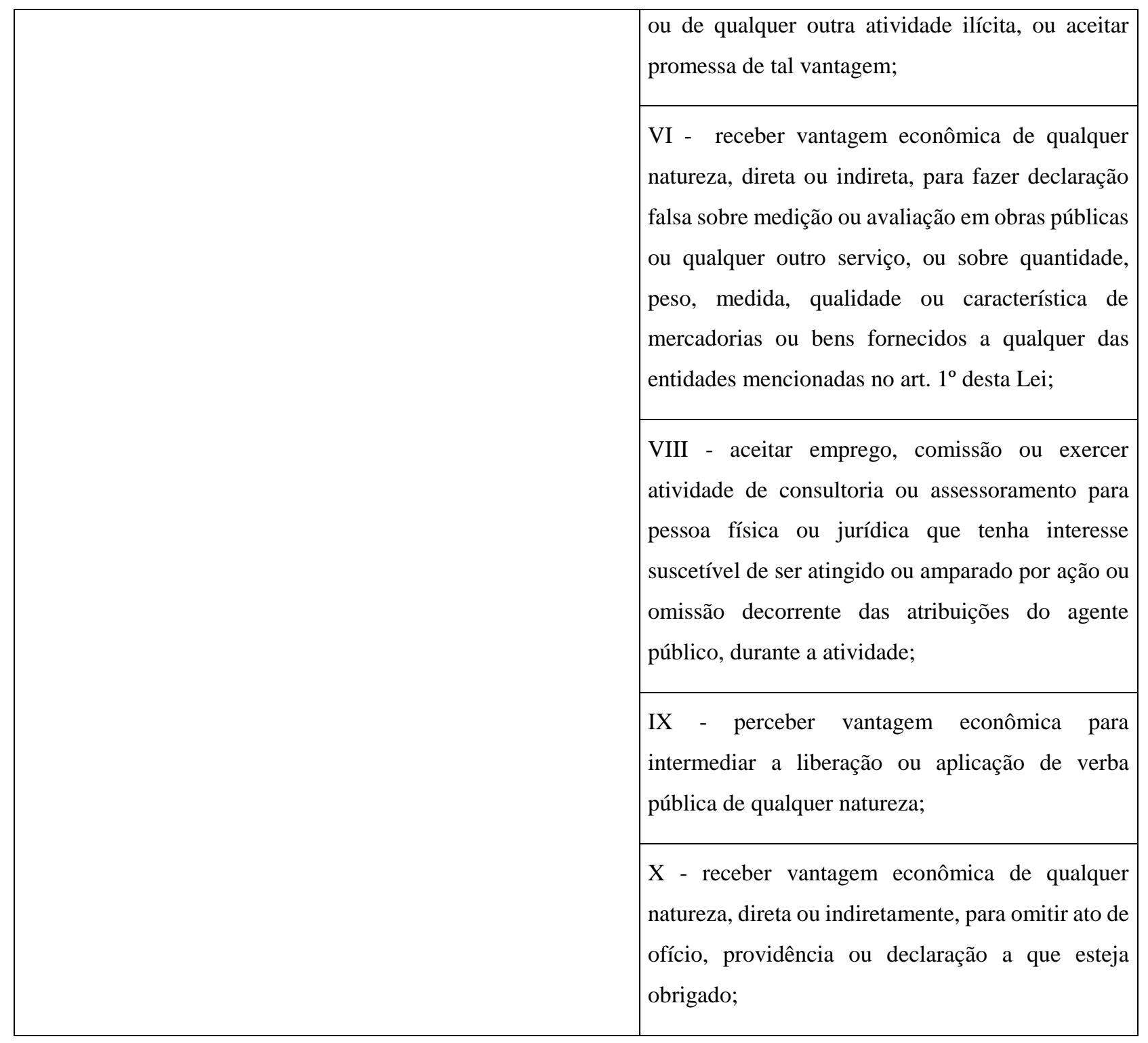

*Tabela 1: comparativo entre a Lei Anticorrupção e a Lei de Improbidade Administrativa

Artigo $5^{\circ}$ da Lei 12.646/2013 - Lei Anticorrupção. Art. $5^{\circ}$ Constituem atos lesivos à administração pública, nacional ou estrangeira, para os fins desta Lei, todos aqueles praticados pelas pessoas jurídicas mencionadas no parágrafo único do art. $1^{\circ}$, que atentem contra o patrimônio público nacional ou estrangeiro, contra princípios da administração pública ou contra os compromissos internacionais assumidos pelo Brasil,
Lei 8.666/93 - Lei de Licitações 


\begin{tabular}{|c|c|}
\hline $\begin{array}{c}\text { assim definidos: } \\
\text { IV - no tocante a licitações e contratos: }\end{array}$ & \\
\hline $\begin{array}{l}\text { a) frustrar ou fraudar, mediante ajuste, combinação ou } \\
\text { qualquer outro expediente, o caráter competitivo de } \\
\text { procedimento licitatório público; }\end{array}$ & $\begin{array}{l}\text { Art. 90. Frustrar ou fraudar, mediante ajuste, combinação } \\
\text { ou qualquer outro expediente, o caráter competitivo do } \\
\text { procedimento licitatório, com o intuito de obter, para si ou } \\
\text { para outrem, vantagem decorrente da adjudicação do objeto }\end{array}$ \\
\hline $\begin{array}{l}\text { b) impedir, perturbar ou fraudar a realização de qualquer } \\
\text { ato de procedimento licitatório público; }\end{array}$ & \\
\hline $\begin{array}{l}\text { c) afastar ou procurar afastar licitante, por meio de } \\
\text { fraude ou oferecimento de vantagem de qualquer tipo; }\end{array}$ & $\begin{array}{l}\text { Art. 92. Admitir, possibilitar ou dar causa a qualquer } \\
\text { modificação ou vantagem, inclusive prorrogação contratual, } \\
\text { em favor do adjudicatário, durante a execução dos contratos }\end{array}$ \\
\hline d) fraudar licitação pública ou contrato dela decorrente; & celebrados com o Poder Público, sem autorização em lei, no \\
\hline $\begin{array}{l}\text { e) criar, de modo fraudulento ou irregular, pessoa } \\
\text { jurídica para participar de licitação pública ou celebrar } \\
\text { contrato administrativo; }\end{array}$ & $\begin{array}{l}\text { ato convocatório da licitação ou nos respectivos } \\
\text { instrumentos contratuais, ou, ainda, pagar fatura com } \\
\text { preterição da ordem cronológica de sua exigibilidade, } \\
\text { observado o disposto no art. } 121 \text { desta Lei }\end{array}$ \\
\hline $\begin{array}{l}\text { f) obter vantagem ou benefício indevido, de modo } \\
\text { fraudulento, de modificações ou prorrogações de } \\
\text { contratos celebrados com a administração pública, sem } \\
\text { autorização em lei, no ato convocatório da licitação } \\
\text { pública ou nos respectivos instrumentos contratuais; ou }\end{array}$ & $\begin{array}{l}\text { Art. 93. Impedir, perturbar ou fraudar a realização de } \\
\text { qualquer ato de procedimento licitatório. }\end{array}$ \\
\hline $\begin{array}{l}\text { g) manipular ou fraudar o equilíbrio econômico- } \\
\text { financeiro dos contratos celebrados com a administração } \\
\text { pública; }\end{array}$ & $\begin{array}{l}\text { Art. 95. Afastar ou procurar afastar licitante, por meio de } \\
\text { violência, grave ameaça, fraude ou oferecimento de } \\
\text { vantagem de qualquer tipo. }\end{array}$ \\
\hline
\end{tabular}

*Tabela 2: comparativo entre a Lei Anticorrupção e a Lei de Licitações

Da análise comparativa dos artigos, se o Ministério Público Federal possui ampla legitimidade para punir eventuais crimes cometidos em detrimento à Administração Pública Federal, de acordo com as atribuições que lhe foram dadas pela Lei de Improbidade Administrativa e pela Lei de Licitações, surge o entendimento de que este também seria legitimado para firmar Acordo de Leniência nos termos da Lei Anticorrupção, ante o fato de que os crimes previstos em seus dispositivos podem ser amplamente punidos na esfera penal. 
Ilustrando esse entendimento, necessária a exposição de trecho do Estudo Técnico $\mathrm{n}^{\circ}$ 01/2017 realizado pela 5 a Câmara de Coordenação e Revisão - Combate à Corrupção do Ministério Público Federal:

Deste modo, é possível que, apesar de ter celebrado acordo de leniência, no processo administrativo sancionador, depois de atendidas as condições e requisitos para tanto (LAC, art. 16, I e II, $\S 1^{\circ}$, I a III), a pessoa jurídica colaboradora ainda esteja, em tese, sujeita à responsabilização judicial das sanções de direito administrativo, que podem ser cumuladas, em ação civil pública, com outras esferas de responsabilidade, como a dos atos de improbidade administrativa, consoante decorre dos estritos termos dos arts. 18, 19 e 30, da LAC.

\section{Conforme concebido pela $5^{\mathrm{a}}$ Câmara de Coordenação e Revisão do Ministério Público} Federal, ainda que firmado o Acordo de Leniência junto à Controladoria Geral da União - CGU, detentora da legitimidade de acordo com a Lei Anticorrupção, as pessoas jurídicas lenientes podem ser demandados posteriormente pelo Ministério Público Federal, pelos mesmos temas que consequentemente já estariam sendo ou até mesmo já teriam sido ressarcidos ao erário público, sob o risco de incorrerem em bis in idem. Os artigos da Lei Anticorrupção no 12.846/2013 que tratam desta possibilidade são, respectivamente, $18^{16}, 19^{17}$ e $30^{18}$.

Nesse sentido, não há razões para que o Ministério Público Federal não seja legitimado para firmar um Acordo de Leniência em conformidade com a Lei Anticorrupção.

\footnotetext{
${ }^{16}$ Art. 18. Na esfera administrativa, a responsabilidade da pessoa jurídica não afasta a possibilidade de sua responsabilização na esfera judicial.

${ }^{17}$ Art. 19. Em razão da prática de atos previstos no art. $5^{\circ}$ desta Lei, a União, os Estados, o Distrito Federal e os Municípios, por meio das respectivas Advocacias Públicas ou órgãos de representação judicial, ou equivalentes, e o Ministério Público, poderão ajuizar ação com vistas à aplicação das seguintes sanções às pessoas jurídicas infratoras: I - perdimento dos bens, direitos ou valores que representem vantagem ou proveito direta ou indiretamente obtidos da infração, ressalvado o direito do lesado ou de terceiro de boa-fé; II - suspensão ou interdição parcial de suas atividades; III - dissolução compulsória da pessoa jurídica; IV - proibição de receber incentivos, subsídios, subvenções, doações ou empréstimos de órgãos ou entidades públicas e de instituições financeiras públicas ou controladas pelo poder público, pelo prazo mínimo de 1 (um) e máximo de 5 (cinco) anos.
}

18 Art. 30. A aplicação das sanções previstas nesta Lei não afeta os processos de responsabilização e aplicação de penalidades decorrentes de: I - ato de improbidade administrativa nos termos da Lei ${ }^{\circ} 8.429$, de 2 de junho de 1992 ; e II - atos ilícitos alcançados pela Lei no 8.666, de 21 de junho de 1993, ou outras normas de licitações e contratos da administração pública, inclusive no tocante ao Regime Diferenciado de Contratações Públicas - RDC instituído pela Lei $\mathrm{n}^{\circ} 12.462$, de 4 de agosto de 2011. 
Além disso, visando reforçar a segurança jurídica que norteia os acordos administrativos, também não há razões para que os órgãos que exercem o controle e a fiscalização da Administração Pública Federal não se reúnam e firmem apenas um instrumento consensual junto às empresas interessadas em colaborarem com a justiça. Com essa união entre os entes, as pessoas jurídicas se sentiriam muito mais confiantes e dispostas a colaborar, visto a segurança que lhes é passada simplesmente pelo fato de que não serão, após colaborarem, requisitadasperante outros órgãos para responderem pelos mesmos atos lesivos já deliberados anteriormente com outro legitimado.

A $5^{\mathrm{a}}$ Câmara de Combate à Corrupção do Ministério Público Federal também se manifestou neste sentido ${ }^{19}$ :

Em razão da autonomia das instâncias de responsabilização, como sabido, é comum que o poder público apresente-se fragmentado, com órgãos diversos, que detêm pretensões sancionadoras distintas. Entretanto, para o particular, sua realidade infracional é una, ainda que informada e reportada a diferentes canais estatais. Para compatibilizá-la com a fragmentação organizacional do Estado, no intuito de se assegurar efetivo equilíbrio às posições de cada parte, deve-se, preferencialmente, efetuar a negociação de um acordo único, transversal, que contemple adequadamente os interesses dos celebrantes e, especialmente, os do ente estatal considerado amplamente e não em razão de cada uma de suas expressões funcionais ou orgânicas.

Igualmente, o Supremo Tribunal Federal afirmou que ${ }^{20}$ :

os princípios da segurança jurídica e da proteção da confiança tornam indeclinável o dever estatal de honrar o compromisso assumido no acordo de colaboração, concedendo a sanção premial estipulada, legítima contraprestação ao adimplemento da obrigação por parte do colaborador.

${ }^{19}$ ESTUDO TÉCNICO No 01/2017. 2017. $5^{\text {a }}$ Câmara de Coordenação e Revisão - Combate à Corrupção do Ministério Público Federal. Disponível em: <http://www.mpf.mp.br/atuacao-tematica/ccr5/publicacoes/estudotecnico/doc/Estudo\%20Tecnico\%2001-2017.pdf>. Acesso em: 18 de out. de 2019.

${ }^{20}$ (SUPREMO TRIBUNAL FEDERAL. Julgamento do Habeas Corpus nº 127.483 em 27/08/2015). 
Deste modo, respaldando-se nos princípios da supremacia do interesse público ${ }^{21}$, da razoabilidade $^{22}$ e da proporcionalidade ${ }^{23}$, o Ministério Público Federal ainda em 2015 passou a celebrar Acordos de Leniências, cujos termos foram devidamente homologados por sua $5^{\mathrm{a}}$ Câmara de Coordenação e Revisão - Combate à Corrupção.

Ademais, frisa-se que o último acordo celebrado por este ente foi devidamente homologado em 05/09/2019, totalizando um número de 29 Acordos de Leniência firmados no âmbito Federal.

Contudo, ao contrário do que ocorre com os acordos firmados pela Controladoria Geral da União - CGU, o Ministério Público Federal tem se deparado com dificuldades para que seus acordos sejam, além de homologados, respeitados pelo Poder Judiciário brasileiro.

\section{O PODER JUDICIÁRIO ANTE AOS ACORDOS DE LENIÊNCIA FIRMADOS EM ÂMBITO FEDERAL}

Como brevemente mencionado anteriormente, o Ministério Público Federaltem encontrado dificuldades perante o Poder Judiciário para que seus Acordos de Leniência sejam reconhecidos,

\footnotetext{
${ }^{21}$ O princípio da supremacia do interesse público sobre o interesse privado é princípio geral de Direito inerente a qualquer sociedade. É a própria condição de sua existência. Assim, não se radica em dispositivo específico algum da Constituição, ainda que inúmeros aludam ou impliquem manifestações concretas dele, como, por exemplo, os princípios da função social da propriedade, da defesa do consumidor ou do meio ambiente (art. 170, III, V e VI), outantos outros. Afinal, o princípio em causa é um pressuposto lógico do convívio social. Para o Direito Administrativo interessam apenas os aspectos de sua expressão na esfera administrativa. Para não deixar sem referência constitucional algumas aplicações concretas especificamente dispostas na Lei Maior e pertinentes ao Direito Administrativo, basta referir os institutos da desapropriação e da requisição (art. XXIV e XXV), nos quais é evidente a supremacia do interesse público sobre o interesse privado. (MELLO, Celso Antônio Bandeira de. Curso de Direito Administrativo. $32^{\mathrm{a}}$. ed. Malheiros Editores Ltda., 2014).

${ }^{22}$ Enuncia-se com este princípio que a Administração, ao atuar no exercício de discrição, terá de obedecer a critérios aceitáveis do ponto de vista racional, em sintonia com o senso normal de pessoas equilibradas e respeitosa das finalidades que presidiram a outorga da competência exercida. Vale dizer: pretende-se colocar em claro que não serão apenas inconvenientes, mas também ilegítimas - e, portanto, jurisdicionalmente invalidáveis - , as condutas desarrazoadas, bizarras, incoerentes ou praticadas com desconsideração às situações e circunstâncias que seriam atendidas por quem tivesse atributos normais da prudência, sensatez e disposição de acatamento às finalidades da lei atributiva da discrição manejada. (MELLO, Celso Antônio Bandeira de. Curso de Direito Administrativo. 32a . ed. Malheiros Editores Ltda., 2014).

${ }^{23}$ Este princípio enuncia a ideia - singela, aliás, conquanto frequentemente desconsiderada - de que as competências administrativas só podem ser validamente exercidas na extensão e intensidade correspondentes ao que seja realmente demandado para cumprimento da finalidade de interesse público a que estão atreladas. Segue-se que os atos cujos conteúdos ultrapassam o necessário para alcançar o objetivo que justifica o uso da competência ficam maculados de ilegitimidade, porquanto desbordam do âmbito da competência; ou seja, superam os limites que naquele caso lhe corresponderiam. (MELLO, Celso Antônio Bandeira de. Curso de Direito Administrativo. 32a . ed. Malheiros Editores Ltda., 2014).
} 
tanto pelos magistrados quanto pela Advocacia Geral da União - AGU, que atua em defesa dos interesses da União Federal, e vem se manifestando pela invalidade dos acordos celebrados e pela continuidade das ações de ressarcimento em face das empresas lenientes.

A Construtora Norberto Odebrecht S/A realizou um Acordo de Leniência junto ao Ministério Público Federal em dezembro de $2016^{24}$, e uma das condições previstas era aplicada ao próprio Ministério Público Federal, para que este se manifestasse nas ações ajuizadas em face da empresa, informando a celebração do acordo, bem como requerendo eventuais desbloqueios de bens e o prosseguimento das ações com efeitos meramente declaratórios.

De início, utilizando uma das ações em que houve o cumprimento por parte do Ministério Público Federal quanto às manifestações, o juiz Federal de primeira instância, Friedman Anderson Wendpap, proferiu decisão favorável ao acordo celebrado ${ }^{25}$, cujo teor merece destaque:

O Estado, seja concebido à luz de conceito sociológico, seja concebido à luz de conceito puramente jurídico, não pode se fragmentar em múltiplos órgãos, cada qual simbolizando a idiossincrasia de seus agentes públicos. O Estado, ou melhor, a Administração Pública é una, e sua subdivisão, ainda que sob o prisma da independência funcional de seus agentes, deve levar em conta que o administrado não pode ficar a mercê de conflito de atribuições internas à pessoa política com quem mantém relações, quer de natureza contratual, quer de natureza legal. Nesse contexto, ao celebrar o acordo de leniência, o Ministério Público Federal age em prol do interesse primário -- e não secundário -- da Administração Pública, que, nocaso, pertence à União. Assim, defendendo interesses em nome da pessoa política -- o que não se assimila à advocacia prestada a ente público --, soa, no mínimo, contraditório a insurgência da Advocacia-Geral da União contra o cumprimento do acordo, cujo fim precípuo é, justamente, facilitar o ressarcimento do dano.Assim, manter o bloqueio implicaria negar eficácia a acordo celebrado com base em legislação técnica, por mera dissidência entre órgãos que compõem o Estado em si (unitariamente concebido), dando ensejo, no mais, a comportamento contraditório por parte da Administração Pública: nemopotestvenire contra factumproprium.

(...)

O Estado brasileiro sói ser a Hidra de Lerna e não o Leviatã de Hobbes. Os particulares expendem esforço hercúleo para lidar com as múltiplas e imprevisíveis cabeças que brotam infinitamente desse monstro. Porém, em alguns

24 TERMO DE ACORDO DE LENIÊNCIA. Ministério Público Federal. Disponível em: <http://www.mpf.mp.br/atuacao-tematica/ccr5/coordenacao/colaboracoes-premiadas-e-acordos-deleniencia/doc_acordos_votos/Acordo_Odebrecht_1.00.000.019193-2016-92.pdf>. Acesso em: 25 de out. de 2019.

${ }^{25}$ Decisão proferida pelo juiz Federal, Friedmann Anderson Wendapp, no âmbito do processo $\mathrm{n}^{\circ}$ 502595671.2016.4.04.7000, em trâmite perante a $1^{\mathrm{a}}$ Vara Federal da Seção Judiciária do Paraná em Curitiba, na data de 24/03/2017. 
momentos o cotidiano esquizofrênico do nosso Estado deve ceder passo à racionalidade e a sua ratioexistendi - prover segurança nas relações intersubjetivas - prevalecer altaneira. Ocasiões em que se faz história e não apenas tange-se a rotina como devir enfadonho. O caso sub oculitem conotações emocionais e políticas de magnitude extraordinária, exigindo das autoridades judiciais forte liame com o princípio de devido processo legal. Inexiste margem para adaptações casuísticas que atendam ao strepitusfori. Previsibilidade, cumprimento da palavra empenhada, honra, são virtudes geradoras de confiança nas relações sociais. Como não adimplir a palavra da União veiculada pelo MPF? Do ponto de vista dos particulares, o Ministério Público da União e a Advocacia Geral da União são indistinguíveis, são o ente União e não o pulmão esquerdo e o direito de um organismo. O particular transacionou com o ente, não com os órgãos. Por isso, a transação entre o Ministério Público Federal e as pessoas que representam o conjunto de Empresas Odebrecht é válido, vigente, imperativo, alcançando todos os órgãos da União, mesmo os que manifestam resistência. Segunda razão. É ainda mais evidente que, uma vez celebrado acordo com o colaborador, em que se pactua o levantamento de constrição, não é concebível manter o bloqueio dos bens do agente apenas em razão de que não houve imputação dos pagamentos, seja na ação de improbidade, seja no acordo de leniência.

Apesar da decisão proferida pelo magistrado ter sido extremamente fundamentada, tendo sido proferida em respeito ao acordo administrativo firmado entre as partes em âmbito Federal, e ainda, em consideração à supremacia do interesse público, afastando qualquer possibilidade de diferenciação entre os órgãos que exercem o controle da Administração Pública, em sede de agravo de instrumento a decisão foi revertida pela Desembargadora Federal Vânia Hack de Almeida ${ }^{26}$, para fazer valer a indisponibilidade de bens, conforme requerimento da Advocacia Geral da União - AGU, sob os seguintes fundamentos:

No acordo de leniência, embora a lei aponte como legitimada a CGU, faz-se necessária a participação de todos os órgãos envolvidos (Ministério Público, Advocacia Pública, Tribunal de Contas) para que a responsabilização seja única e integral.Contata-se, dessa maneira, vício no acordo de leniência sob exame, o que, entretanto, não leva à nulidade do ato negocial, pela possibilidade de ratificação pela CGU, ou re-ratificação, com participação dos demais entes, levando-se em conta o aspecto a seguir examinado, qual seja o ressarcimento ao erário e a multa.Afasta-se a nulidade absoluta do negócio jurídico também em respeito ao princípio da segurança jurídica e da proteção da confiança, conforme acima mencionado. $\mathrm{O}$ acordo de leniência firmado não pode ser uma armadilha para a empresa que recebe o lenitivo.

\section{$(\ldots)$}

\footnotetext{
${ }^{26}$ Decisão proferida pela Desembargadora Federal, Vânia Hack de Almeida, no âmbito do agravo de instrumento ${ }^{\circ}$ 5023972-66.2017.4.04.0000, em trâmite perante o Tribunal Regional Federal da 4 ${ }^{a}$ Região, na data de 28/08/2017.
} 
Em princípio, portanto, a empresa deverá permanecer na ação de improbidade, aguardando-se eventual ratificação ou re-ratificação do Acordo de Leniência, persistindo o interesse no bloqueio dos bens, não porque o MP não pode transacionar sobre as penas, como referiu a decisão anterior, mas porque o Acordo de Leniência possui vícios que precisam ser sanados para que resulte íntegra sua validade, gerando os efeitos previstos naquele ato negocial.

\section{(...)}

Em outras palavras, busca-se o ressarcimento dos danos causados ao erário público. O bloqueio de bens é um instrumento adequado para tal intento. Por ora, enquanto não sanados os vícios no acordo de leniência, não há outro meio, que permita atingir-se ao fim colimado. E, por fim, prepondera aqui o interesse público sobre o particular.

Ou seja, o referidoacórdão afastou todo o conceito de que os órgãos que exercem o controle da Administração Pública Federal são uma única repartição, intensificando o conflito entre os entes que, em tese, deveriam se unir.

Em contrapartida, a Controladoria Geral da União - CGU não vem encontrando a mesma dificuldade, ante a legitimidade que lhe foi atribuída pela Lei Anticorrupção. No mesmo sentido das decisões anteriores, o Tribunal Regional Federal ad $4^{\mathrm{a}}$ Região ao homologar um acordo firmado também entre a Construtora Norberto Odebrecht S/A e a Controladoria Geral da União e determinar a suspensão dos bloqueios recaídos nos bens da empresa, também se manifestou quanto aos possíveis vícios existentes nos Acordos de Leniência firmados pelo Ministério Público Federal e, ainda, reconheceu a necessidade que os órgãos de controle possuem de agirem em conjunto ${ }^{27}$.

1. A autoridade competente para firmar o acordo de leniência, no âmbito do Poder Executivo Federal é a Controladoria Geral da União (CGU).

2. Não há impedimentos para que haja a participação de outros órgãos da administração pública federal no acordo de leniência como a Advocacia Geral da União, o Ministério Público Federal e o Tribunal de Contas da União, havendo, portanto, a necessidade de uma atuação harmônica e cooperativa desses referidos entes públicos.

3. Enquanto não houver a re-ratificação dos acordos de leniência, as empresas requeridas deverão permanecer na ação de improbidade, não porque o MP não pode transacionar sobre as penas, mas porque o referido acordo possui vícios que precisam ser sanados para que resulte íntegra sua validade, gerando os efeitos previstos naquele ato negocial.

4. Tendo em vista os termos do Acordo de Leniência firmado entre a CGU/AGU e as empresas requeridas e que neste estão abrangidos para fins de ressarcimento

\footnotetext{
${ }^{27}$ Decisão proferida pela Desembargadora Federal, Vânia Hack de Almeida, no âmbito do agravo de instrumento $n^{\circ}$ 5039527-89.2018.4.04.0000, em trâmite perante o Tribunal Regional Federal da $4^{\text {a }}$ Região, na data de 26/02/2019.
} 
os contratos apontados na ação de improbidade e/ou medida cautelar de arresto, a irresignação da PETROBRAS não afasta a necessidade de prestigiar o acordo de leniência firmado entre as partes e nem revela-se suficiente para a pretendida manutenção da indisponibilidade de bens anteriormente decretada.

5. Se, por um lado, temos a prevalência da supremacia do interesse público (que busca, além do ressarcimento ao Erário e a reparação dos danos causados ao patrimônio público, a punição dos envolvidos) sobre os interesses particulares, tem-se, por outro, a necessidade de prestígio ao acordo de leniência já firmado, que, ao oferecer um lenitivo nas penas administravas para as empresas colaboradoras, tem em troca informações relevantes ao interesse público.

Exposto o conflito existente no âmbito do Poder Judiciário entre os órgãos que exercem o controle da Administração Pública, é significativo tecer uma breve análise quanto ao interesse do Tribunal de Contas da União.

\section{O TRIBUNAL DE CONTAS DA UNIÃO - TCU}

O Tribunal de Contas da União- TCU é um órgão de controle externo que aprecia, fiscaliza e julga as contas públicas, no que tange às contas contábeis, financeiras, orçamentárias, operacionais e patrimoniais da União Federal e das entidades da administração pública direta e indireta $^{28}$. Sua principal função é analisar as referidas contas quanto à legalidade, legitimidade, economicidade, aplicação das subvenções e renúncia de receitas (artigos 70 e 71 da Constituição Federal).

Nesse sentido ${ }^{29}$ :

O Tribunal de Contas da União é órgão auxiliar do Poder Legislativo em sua função fiscalizadora financeira, orçamentária, contábil, operacional e patrimonial dos blocos orgânicos constitucionais, quando em relação a suas atividades administrativas. Essa atividade realizada pelo Legislativo com a colaboração do Órgão de Controle é denominada, também, de "controle externo", assim explicado por Hely Lopes Meirelles. "É o que se realiza por um Poder ou órgão constitucional independente funcionalmente sobre a atividade administrativa de outro Poder estranho à Administração responsável pelo ato controlado

\footnotetext{
${ }^{28}$ Nos termos do Decreto-lei 200, Administração direta é a "que se constitui dos serviços integrados na estrutura administrativa da Presidência da República e dos Ministérios" (art. $4^{\circ}$, I), e Administração indireta "é a que compreende as seguintes categorias de entidades dotadas de personalidade jurídica própria: a) Autarquias; b) Empresas Públicas; c) Sociedades de Economia Mista; d) Fundações Públicas" (art. 4º II). (MELLO, Celso Antônio Bandeira de. Curso de Direito Administrativo. 32a . ed. Malheiros Editores Ltda., 2014).

${ }^{29}$ SALOMÃO, Eduardo Mendonça. Os Tribunais de Contas, jurisdição e eficácia e efetividade de suas decisões. 2016. Dissertação (Mestrado em Direito) - Universidade Estadual Paulista Júlio de Mesquita Filho, Franca, 2016.
} 
(MEIRELLES, Hely Lopes. Direito administrativo brasileiro. 30. ed. São Paulo: Malheiros, 2005. p. 647.) “

Deste modo, todos os atos praticados pela Administração Pública Federal, direta ou indireta, passam pelo controle dos Tribunal de Contas da União e, ressalta-se que sua atuação é devidamente regulamentada pela Lei Orgânica n ${ }^{\circ}$ 8.443/92.

Além do controle de fiscalização, o Tribunal de Contas da União também possui competência para aplicar eventuais sanções aos administradores ou responsáveis pelas irregularidades apuradas. Essas sanções podem consistir em: (i) aplicação de multa; (ii) declaração de inidoneidade; (iii) decretação de indisponibilidade de bens (artigos 57, 58, 59, 60 e 61 da Lei no 8.443/92).

Nesse cenário, em razão do Acordo de Leniência ser firmado em âmbito Federal e tratar de ressarcimento de danos causados ao erário público Federal, entende-se que também é de competência do Tribunal de Contas da União fiscalizar os acordos celebrados. Para regulamentar esta questão, foi publicada a Instrução Normativa n $74 / 2015$, a qual posteriormente foi substituída pela Instrução Normativa n ${ }^{\circ}$ 83/2018.

A Instrução Normativa publicada dispõe sobre a fiscalização pelo Tribunal de Contas da União dos processos de negociação de Acordos de Leniência e dos termos firmados após concluída a colaboração. Ainda, a Instrução Normativa prevê que os entes de controle que firmarem um acordo com cláusulas que dificultem ou limitem a atuação do Tribunal, poderão ser devidamente responsabilizados (Lei 8.443/92).

Posto isto, o Tribunal de Contas da União vem chancelando acordos celebrados em âmbito Federal, ainda que o entendimento quanto à sua atuação não esteja consolidado. Entretanto, aplicase ao Tribunal de Contas da União as mesmas circunstânciasaplicadas ao Ministério Público Federal, pois ambos são órgãos de controle da Administração Pública Federale possuem plena legitimidade para perseguirem e punirem agentes envolvidos em atos ilícitos praticados em detrimento ao patrimônio público.

Por esta razão, entende-se que o Tribunal de Contas da União também seria legítimo para firmar um Acordo de Leniência, mesmo que a Lei Anticorrupção não tenha lhe atribuído a mesma legitimidade que atribuiu à Controladoria Geral da União - CGU, pelo simples fato de que, não 
participando das negociações, não poderá deixar de demandar e responsabilizar as empresas lenientes, trazendo-nos novamente à esfera da insegurança jurídica.

Nessa premissa, por falta de regulamentação quanto à atuação do Tribunal de Contas da União na realização dos Acordos de Leniência, a Controladoria Geral da União vem inserindo em seus acordos de Leniência a seguinte disposição, conforme consta nos termos do Acordo de Leniência firmado junto à empresa Andrade Gutierrez Investimentos em Engenharia S/A ${ }^{30}$ :

As INSTITUIÇÕES CELEBRANTES e as RESPONSÁVEIS COLABORADORAS reconhecem que, de acordo com as vontades aqui livremente expressas, a assinatura do presente Acordo de Leniência não afasta nem interfere no exercício das competências do Tribunal de Contas da União TCU, fixadas no artigo 71 da Constituição, observadas, ainda, as Cláusulas 13.4 e 13.5.

Tal disposição ressalta a competência que o Tribunal de Contas da União possui para fiscalizar e aplicar eventuais sanções aos responsáveis envolvidos nos atos ilícitos em matérias que podem constar dos Acordos de Leniência firmados. Sendo assim, se o Tribunal de Contas da União possui legitimidade para os referidos atos, consequentemente deveria possuir também legitimidade para celebrar instrumentos consensuais de Leniência.

\section{CONSIDERAÇÕES FINAIS}

Diante de todo o exposto, resta claro que a legitimidade para firmar Acordo de Leniência é inteiramente da Controladoria Geral da União - CGU, conforme previsão expressa na Lei Anticorrupção no $12.846 / 13$.

Entretanto, há outros órgãos de controle dos interesses da Administração Pública Federal, que, por tratarem de assuntos cujos termos também podem ser avençados em Acordos de Leniência,

\footnotetext{
${ }^{30}$ ACORDO DE LENIÊNCIA FIRMADO ENTRE O MINISTÉRIO DA TRANSPARÊNCIA E CONTROLADORIA GERAL DA UNIÃO (CGU), A ADVOCACIA GERAL DA UNIÃO (AGU) E AS EMPRESAS ANDRADE GUTIERREZ INVESTIMENTOS EM ENGENHARIA S/A, ANDRADE GUTIERREZ ENGENHARIA S/A e ANDRADE GUTIERREZ S/A. Controladoria Geral da União. Disponível em <http://www.cgu.gov.br/assuntos/responsabilizacao-de-empresas/lei-anticorrupcao/acordo-leniencia/acordosfirmados/andrade-gutierrez.pdf $>$. Acesso em: 23/10/2019.
} 
entendem-se legitimados para tanto. Os órgãos de controle que compõem este conflito, consoante demonstrado anteriormente, compreendem: (i) a Advocacia Geral da União - AGU; (ii) o Ministério Público Federal e; (iii) o Tribunal de Contas da União.

Tendo como base a análise feita no curso deste artigo, conclui-se que não há razões para que os referidos órgãos de controle em âmbito Federal não possam transigir e firmar um Acordo de Leniência junto às pessoas jurídicas envolvidas nos atos ilícitos, ante a dimensão de suas competências.

Por entenderem da mesma maneira, estes órgãos estão adotando medidas para que possam se aproximar da Controladoria Geral da União quando da celebração dos acordos, visando a unicidade da atuação da Administração Pública Federal, em proteção à segurança jurídica e ao incentivo às colaborações que contribuem - e muito - para o bom funcionamento da justiça.

Diante disso, a Controladoria Geral da União - CGU também vem respeitando os demais acordos administrativos que versam sobre interesses Federais. Para tanto, vem inserindo em seus termos uma ressalva quanto aos acordos anteriormente firmados, e, ainda, há um abatimento do valor fixado a título de ressarcimento ao erário público às empresas lenientes.

Em uma das cláusulas presentes no Acordo de Leniência celebrado pela Controladoria Geral da União junto à empresa Andrade Gutierrez Investimentos em Engenharia S/A ${ }^{31}$, há confirmação quanto a atual posição da Controladoria Geral da União, mediante a seguinte disposição:

8.3. Tendo em vista o disposto no item 7.1, e considerando que os fatos objeto do Acordo da PRIMEIRA RESPONSÁVEL COLABORADORA com o Ministério Público Federal (MPF) também integram o presente Acordo, será deduzido do valor definido neste Acordo de Leniência o montante da dívida já assumida pela PRIMEIRA RESPONSÁVEL COLABORADORA junto ao MPF, incluindo as três parcelas vencidas e já pagas, devidas, respectivamente, em 28/06/2016, 28/06/2017 e 28/06/2018, as quais, para esses fins, serão atualizadas até a data-

\footnotetext{
${ }^{31}$ ACORDO DE LENIÊNCIA FIRMADO ENTRE O MINISTÉRIO DA TRANSPARÊNCIA E CONTROLADORIA GERAL DA UNIÃO (CGU), A ADVOCACIA GERAL DA UNIÃO (AGU) E AS EMPRESAS ANDRADE GUTIERREZ INVESTIMENTOS EM ENGENHARIA S/A, ANDRADE GUTIERREZ ENGENHARIA S/A e ANDRADE GUTIERREZ S/A. Controladoria Geral da União. Disponível em <http://www.cgu.gov.br/assuntos/responsabilizacao-de-empresas/lei-anticorrupcao/acordo leniencia/acordos-
} firmados/andrade-gutierrez.pdf $>$. Acesso em: 25/10/2019. 
base utilizada para fixação do valor de que trata a Cláusula 8.2 e conforme Anexo IV.

Essa iniciativa, além de reforçar o entendimento aqui discutido, demonstra o interesse que os órgãos de controle da Administração Pública Federal possuem em sua atuação em conjunto, ou até mesmo independente, porém de maneira pacífica. Nesse sentido, imprescindível ressaltar os resultados positivos que a Controladoria Geral da União e o Ministério Público Federal obtiveram nos últimos anos com a realização dos Acordos de Leniência.

Portanto, abaixo a demonstração do balanço e monitoramento disponibilizado pela própria Controladoria Geral da União ${ }^{32}$ :

* Figura - balanço e monitoramento - atualizado em JUL/2019

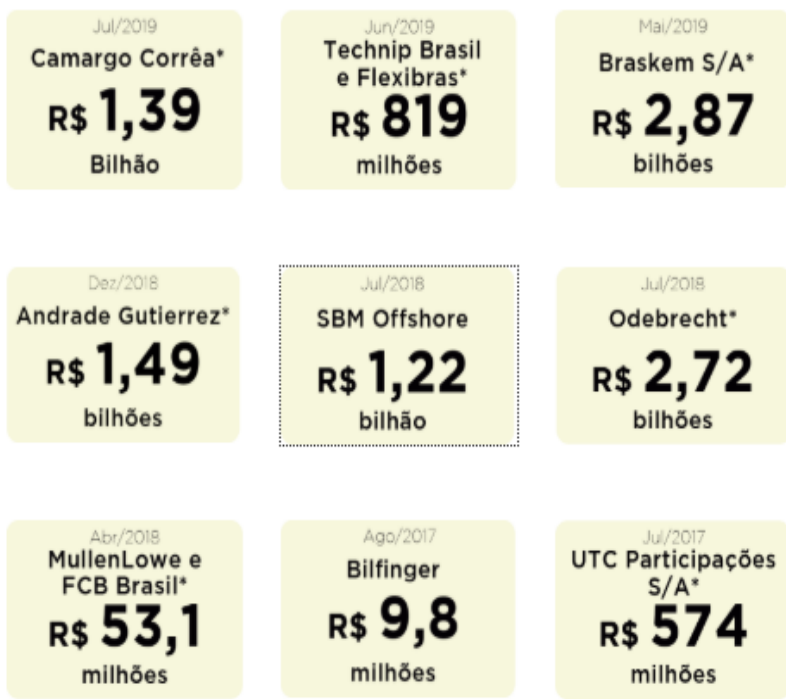

\section{TOTAL: R\$ 11,15 BILHÕES}

Os valores a serem ressarcidos envolvem os
gamentos de multa, dano e enriquecimento ilicito

Enpresas investigadas no ämbito da Lava lato

32 ACORDO DE LENIÊNCIA. Controladoria Geral da União - CGU. Disponível em: <http://www.cgu.gov.br/assuntos/responsabilizacao-de-empresas/lei-anticorrupcao/acordo-leniencia>. Acesso em 27/10/2019. 
Por outro lado, como visto anteriormente, somente essa aproximação entre os entes de controle não basta para conferir segurança jurídica aos acordos celebrados. É necessário que haja a edição de um instrumento normativo regulamentando essas relações, visando estabelecer as diretrizes que deverão ser tomadas para o início das tratativas, para as negociações e para a final celebração do Acordo de Leniência. Com essa regulamentação, além de aprimorar e amadurecer os meios brasileiros consensuais de resolução de conflitos, não restarão margens para eventuais discussões acerca da validade e legitimidade dos acordos firmados em âmbito Federal.

Todavia, por mais que os órgãos de controle se esforcem para estabelecerem parcerias, a busca por protagonismo ante aos destaques conferidos aos assuntos objetos dos acordos, amplamente divulgados através das mídias sociais, vem crescendo cada vez mais, com contribuição, em especial, do interesse da população brasileira pela transparência dos atos praticados pelo Poder Público. Tal disputa, ainda que amenizada pelas novas práticas de parcerias estabelecidas, ainda é um dos principais meios que impossibilitam a evolução do instrumento consensual da leniência.

Por fim, ressalta-se novamente a importância da atuação dos órgãos de controle da Administração Pública Federal em conjunto, com a necessidade da devida inserção de uma regulamentação perante o ordenamento jurídico brasileiro,em proteçãoà supremacia do interesse público eà confiabilidade atribuída à segurança jurídica, visando respeito práticoaos termos compactuados para que se alcance o devido cumprimento dos Acordos de Leniência firmados em âmbito Federal.

\section{REFERÊNCIAS}

CARVALHO FILHO, José dos Santos. Manual de direito administrativo. 31. edição. São Paulo. Editora Atlas, 2017.

DIPP, Gilson. Comentários sobre a Lei Anticorrupção. Gilson Dipp, Manoel L.Volkmer de Castilho. São Paulo. Editora Saraiva, 2016.

ESTUDO TÉCNICO No 01/2017. $5^{\text {a }}$ Câmara de Coordenação e Revisão - Combate à Corrupção do Ministério Público Federal. Disponível em: <http://www.mpf.mp.br/atuacao- 
tematica/ccr5/publicacoes/estudo- tecnico/doc/Estudo\%20Tecnico\%2001-2017.pdf $>$. Acesso em 15/10/2019.

GARCIA, Emerson. Ministério Público: organização, atribuições e regime jurídico. Emerson Garcia. $6^{a}$ edição. São Paulo. Editora Saraiva, 2017.

MELLO, Celso Antônio Bandeira de. Curso de Direito Administrativo. 32ª . ed. Malheiros Editores Ltda., 2014.

MUNIZ, Fernanda Eduardo Olea do Rio; MUNIZ, Antônio Walber Matias. REPERCUSSIONS OF THE APPROVAL OF THE STRUCTURE OF THE MERCOSUR INSTITUTE OF PUBLIC POLICIES ON HUMAN RIGHTS BY THE BRAZILIAN GOVERNMENT. Revista Juridica, [S.1.], v. 1, n. 54, p. 51 - 72, mar. 2019. ISSN 2316-753X. Disponível em: <http://revista.unicuritiba.edu.br/index.php/RevJur/article/view/3300/371371793>. Acesso em: 20 abr. 2020. doi:http://dx.doi.org/10.21902/revistajur.2316-753X.v1i54.3300.

NOTA TÉCNICA No 01/2017. $5^{\text {a }}$ Câmara de Coordenação e Revisão - Combate à Corrupção do Ministério Público Federal. Disponível em: <http://www.mpf.mp.br/atuacao-tematica/ccr5/notastecnicas/docs/nt-01-2017-5ccr-acordo-de-leniencia-comissao-leniencia.pdf $>$ Acesso em 15/10/2019.

OLIVEIRA, Matheus Manelli de. A controvérsia acerca da natureza do Tribunal de Contas da União e suas decisões. Artigo científico apresentado como requisito à obtenção de grau de Bacharel em Direito pela Pontifícia Universidade Católica do Rio Grande do Sul (PUCRS), aprovado em 05 jul. 2019. Disponível em: <http://www.pucrs.br/direito/wpcontent/uploads/sites/11/2019/09/matheus_oliveira.pdf>. Acesso em: 15 out. 2019.

ROSILHO, André. Tribunal de Contas da União - Competências, Jurisdição e Instrumentos de Controle. São Paulo. Editora QuartierLatin, 2019.

SALOMÃO, Eduardo Mendonça. Os Tribunais de Contas, jurisdição e eficácia e efetividade de suas decisões. 2016. Dissertação (Mestrado em Direito) - Universidade Estadual Paulista Júlio de Mesquita Filho, Franca, 2016. 
SILVEIRA, Renato de Mello Jorge. Compliance, direito penal e lei anticorrupção. Renato de Mello Jorge Silveira, Eduardo Saad-Diniz. São Paulo. Editora Saraiva, 2015.

SIMÃO, Valdir Moysés. O acordo de leniência na lei anticorrupção (livro eletrônico): histórico, desafios e perspectivas. Valdir Moysés Simão, Marcelo Pontes Vianna. São Paulo. Trevisan Editora, 2017. 